\title{
Redes e capital social: usos possíveis e eventuais limitações enquanto categorias sociológicas
}

\author{
Attila Magno e Silva Barbosa ${ }^{1}$
}

Angelo Martins Jr. ${ }^{2}$

Resumo: No cenário configurado pela globalização é disseminada e fortalecida aquela que em ciências sociais denomina-se cultura de redes. Aqui, nos referimos, sobretudo, às redes de sociabilidade e de cooperação compostas pela união de agentes que se integram horizontalmente e que formulam modelos de organização pautados pela colaboração e por uma lógica de desenvolvimento integrado de sistemas socioeconômicos que possibilitam arranjos produtivos alternativos e solidários. $\mathrm{O}$ espraiamento e o fortalecimento dessa cultura de redes permite gestar formas mais participativas e efetivas de exercício da democracia, assim como de inserção social. Nas sociedades contemporâneas as redes atuam diretamente na estruturação de novas formas de relações sociais, configurando e, ao mesmo tempo, sendo configuradas pela intensificação dos fluxos econômicos, culturais, informacionais e migratórios promovidos pela globalização. Entre outras coisas, elas possibilitam a constituição de formas de integração de indivíduos e de grupos sociais que se voltam para a minimização dos custos de transação inerentes ao intercâmbio das experiências humanas.

\footnotetext{
1 Departamento de Sociologia e Política e do Programa de Pós-Graduação em Sociologia da Universidade Federal de Pelotas - Pelotas - Brasil - barbosaattila@hotmail.com

2 Department of Sociology of Goldsmiths College, University of London - Londres - Reino Unido - martins.ajunior@gmail.com
} 
Assim, o objetivo deste artigo, apresentado na forma de um ensaio bibliográfico, é verificar os usos e as limitações do conceito de rede e do seu correlato capital social enquanto categorias sociológicas explicativas de questões ligadas ao desenvolvimento socioeconômico, à inserção dos indivíduos no mercado de trabalho e aos processos migratórios.

Palavras-chaves: Redes; capital social; desenvolvimento socioeconômico; mercado de trabalho; redes migratórias.

\section{SOCIAL NETWORKS AND SOCIAL CAPITAL: POSSIBLE USES AND LIMITATIONS AS SOCIOLOGICAL CATEGORIES}

Abstract: The aim of this article, written and organised as a bibliographic essay, is to discuss the uses and limitations of the concepts social network and its correlative concept, social capital, as explanatory sociological categories regarding issues related to socio-economic development, to individuals inclusion in the labour market as well as to migration process. Within a context of Globalisation, it has been widespread and reinforced in the social sciences the idea of a "network culture". Here, we refer, in particular, to networks of sociability and cooperation made by the association of agents that horizontally integrate and formulate organizational models guided by collaboration and by a logic of integrated development of socio-economic systems that allow alternative solidarity arrangements of production. The spreading and strengthening of network culture would allow the management of more participatory and effective forms of exercising democracy, as well as promoting social inclusion. In contemporary societies social networks are taken as working directly in the structuring of new forms of social relations, both setting as well as being settled by the intensification of economic, cultural and informational flows as well as by the increase of migration process promoted by globalization. Moreover, social networks would enable the creation of forms of integration of individuals and social groups who seek to minimise the transaction costs related to the exchange of human experience. Thus, this paper tends to critically analyse the role of social network, as well as social capital, in studies on socio-economic development, labour market and migration process.

Key-Words: Social Networks; Social capital; socio-economic development; labour market; migratory networks. 


\section{Introduç̃̃̃o}

A globalização, ao mesmo tempo em que favorece o fortalecimento dos mercados, quando da disseminação de padrões técnicos, gerenciais e de consumo em escala global, também torna possível um maior intercâmbio social e cultural entre grupos e indivíduos. Por isso, não devemos cair na armadilha de reduzi-la aos limites estritos de sua dimensão econômica, por mais fundamental que esta lhe seja enquanto característica. A despeito das críticas que lhe são feitas, devido ao caráter neoliberal por vezes assumido, não se pode negar que ela possibilita a criação de fóruns mundiais de debate sobre problemas sociais, políticos e econômicos e, consequentemente, o aparecimento de formas de organização coletiva mais bem informadas e críticas em relação às forças do mercado. Nesse sentido, para Giddens (2000), promover mais globalização significa trabalhar os seus pontos positivos, quais sejam: a intensificação dos fluxos informacionais; o estímulo a uma maior interação entre as culturas; e a promoção de ações voluntárias que estimulem a participação maciça nesses processos. Quando a articulação desses pontos ocorre, bloqueando o acesso das pessoas de baixa renda aos benefícios gerados pelas inovações tecnológicas e pelo maior intercâmbio econômico, social e cultural, o que se vê é o reforço de desigualdades sociais.

Nos cenários sociais, políticos e econômicos configurados pela globalização, aquilo que em ciências sociais é chamado de cultura de redes é disseminado e fortalecido. Aqui, nos referimos, sobretudo, às redes de sociabilidade e de cooperação compostas por agentes que se integram horizontalmente e que promovem formas de organização pautadas pela colaboração e por uma lógica de desenvolvimento integrado de sistemas socioeconômicos que possibilitam arranjos produtivos alternativos e solidários. $\mathrm{O}$ espraiamento e o fortalecimento dessas redes permitem gestar formas mais participativas e efetivas de exercício da democracia, assim como de inserção social.

Antes de prosseguirmos, e apenas para efeito de situar-nos, cabe lembrar-nos que o conceito de rede não é uma novidade nas ciências sociais; ele remete à utilização pioneira do antropólogo social britânico John Arundel Barnes, quando da publicação em 1954 do artigo "Class and Committees in a Norwegian Island Parish". Para usarmos as palavras do próprio autor: "a imagem que eu tenho é a de um conjunto de pontos, alguns dos quais estão ligados por linhas. Os pontos da imagem são pessoas ou às vezes grupos e as linhas indicam quais pessoas interagem entre si” (1954: 43). Em outro momento, Barnes complementa: "uma atividade cooperativa exige algum grau de liderança e consenso, seja ela 
realizada por grupos duráveis ou por agrupamentos efêmeros que estão ligados por uma rede de laços sociais" (ibid.: 48). Em outras palavras, uma rede corresponde ao conjunto de relações estabelecidas entre indivíduos e grupos sociais que possibilita a promoção de atividades cooperativas.

Dito isso, voltemos a considerar que, em um mundo cada vez mais interconectado, as redes possibilitam formas de organização que permitem desenvolver modalidades de ação política, econômica e simbólica nas quais os agentes podem mobilizar e fortalecer valores compartilhados e identidades específicas. Nesse sentido, elas contribuem para a promoção de um cenário de maior confiança interpessoal, condição basilar para o fortalecimento de formas de cooperação social.

Nas sociedades contemporâneas, as redes atuam diretamente na estruturação de novas formas de relações sociais, configurando e, ao mesmo tempo, sendo configuradas pela intensificação dos fluxos econômicos, culturais, informacionais e migratórios promovidos pela globalização. Entre outras coisas, possibilitam à constituição de formas de integração de indivíduos e de grupos sociais que se voltam para a minimização dos custos de transação inerentes ao intercâmbio das experiências humanas. Entretanto, não podemos desconsiderar que as redes também promovem um conjunto de coerções e constrangimentos que incide sobre as ações dos agentes socais (indivíduos ou grupos), instaurando, assim, formas de controle e de exclusão que podem contribuir para reproduzir e reforçar desigualdades.

Partindo desse argumento, o objetivo deste artigo, apresentado aqui na forma de ensaio bibliográfico, é lançar luz sobre o conceito de rede e de seu correlato capital social, levando em conta as definições e os usos que lhe são atribuídos no âmbito das ciências sociais. Desse modo, propomos avançar no debate considerando que no terreno empírico das ações e interações sociais, a dualidade acesso/ inclusão e controle/ exclusão, característica inerente às redes, apresenta-se de modo contínuo e concomitante na constituição de um emaranhado de possibilidades e constrições para os indivíduos. Para os fins de nossa proposta, nos debruçaremos especificamente sobre as discussões referentes aos temas do desenvolvimento socioeconômico, da inserção no mercado de trabalho e dos processos migratórios.

\section{0 padrão de organização em redes nas sociedades contemporâneas}

No que se refere aos seus aspectos sociais, a globalização promove a tessitura de formas de sociabilidade nas quais indivíduos e grupos interconectam-se 
por fluxos informacionais que tornam possíveis o trânsito pelo mundo sem que necessariamente haja o deslocamento físico de suas localidades de origem. Ela encontra-se estruturada por um padrão de organização reticular que intensifica a interconexão e a interdependência dos fluxos de capitais, de tecnologias, de interação organizacional, de informações, de símbolos e de pessoas. Para o sociólogo espanhol Manuel Castells, tais fluxos "não representam apenas um elemento da organização social: são a expressão dos processos que dominam nossa vida econômica, política e simbólica" (2002: 501). Como decorrência disso, emerge:

Uma nova forma espacial característica das práticas sociais que dominam e moldam a sociedade em rede: o espaço de fluxos. O espaço de fluxos é a organização material das práticas sociais de tempo compartilhado que funcionam por meio de fluxos. Por fluxos, entendo as sequências intencionais, repetitivas e programáveis de intercâmbio e interação entre posições fisicamente desarticuladas, mantidas por atores sociais nas estruturas econômicas, política e simbólica da sociedade. Práticas sociais dominantes são aquelas que estão embutidas nas estruturas sociais dominantes. Por estruturas sociais dominantes, entendo aqueles procedimentos organizacionais e instituições cuja lógica interna desempenha papel estratégico na formulação das práticas sociais e da consciência social para a sociedade geral (CASTELLS, 2002: 501).

Para Castells, este espaço de fluxos possui três camadas de suporte material: $1^{\mathrm{a}}$ ) um circuito de impulsos eletrônicos (microeletrônica, telecomunicações, processamento computacional, sistema de transmissão e transporte em alta velocidade - também com base em tecnologias de informação), que formam a base material dos processos do padrão organizacional em rede; $2^{\mathrm{a}}$ ) os centros de comunicações, que funcionam como os nós que ligam os espaços de fluxos e exercem funções estratégicas, sendo que a localização destes espaços inscreve-se em uma rede eletrônica que conecta lugares específicos com características sociais, culturais, físicas e funcionais definidas e; $3^{\mathrm{a}}$ ) a organização espacial das elites gerenciais dominantes, pois mesmo que esta não seja a única lógica espacial existente, representa os interesses e as funções dominantes. Este domínio baseia-se na capacidade de organizar a sociedade a partir dos fluxos correspondentes aos interesses das grandes corporações globais e de desorganizar outros grupos sociais, ao ponto destes terem seus interesses parcialmente representados em uma estrutura organizada para 0 atendimento dos interesses dominantes. 
A articulação das elites e a segmentação e desorganização da massa parecem ser os mecanismos gêmeos de dominação social em nossas sociedades. Em resumo: as elites são cosmopolitas, as pessoas são locais. Os espaços de poder e riqueza são projetados pelo mundo, enquanto a vida e a experiência das pessoas ficam enraizadas em lugares, em sua cultura, em sua história. Portanto, quanto mais uma organização social baseia-se em fluxos históricos, substituindo a lógica de qualquer lugar específico, mais a lógica do poder global escapa ao controle sociopolítico das sociedades locais/ nacionais historicamente específicas (CASTELLS: 505).

Aqui, as redes são vistas como formas de organização em plena adequação à economia capitalista globalizada, pois, ao mesmo tempo em que fomentam constantes inovações nas mais diferentes frentes, também possibilitam a concentração descentralizada dos fluxos. Elas estariam no cerne da estruturação de uma morfologia social na qual as operações e os resultados dos processos econômicos, sociais, políticos e culturais são substancialmente modificados. $\mathrm{O}$ fortalecimento do padrão de organização em redes decorreria do fato de que:

As redes facilitam um comportamento coordenado, sem a necessidade de aceitar a rigidez de organizações inflexíveis e burocráticas. A rede mostra-se como única estrutura de ação capaz de cumprir duas funções básicas: primeiro, a função estratégica de reduzir incertezas com relação ao comportamento de outros atores, como competidores ou parceiros; segundo, a função instrumental de melhoria do desempenho, isto é, um aumento dos resultados produzidos. Além disso, as redes parecem preservar a autonomia dos parceiros e aumentar sua capacidade de aprendizagem (FREY, 2003: 175).

Nessa linha interpretativa, as redes são entendidas como formas independentes de coordenação de interações, baseadas na confiança mútua entre agentes sociais autônomos e interdependentes. Devido aos períodos limitados de orquestração das ações em conjunto em torno de objetivos comuns, elas possibilitariam uma maior efetividade na consecução dos interesses dos envolvidos.

Apesar do potencial agregador do padrão de organização em redes, é preciso considerar que, quando entendidas como constitutivas de uma morfologia social reforçada pelas novas tecnologias de informação, elas ainda não afastaram a possibilidade de constituírem novas formas de exclusão social. Segundo dados da União Internacional de Comunicações, ${ }^{3}$ referentes aos anos de 2000 
a 2015, houve um aumento expressivo do acesso à internet ao redor do mundo. Em 2000, o número de usuários era de 400 milhões, equivalente a $6,5 \%$ da população mundial. Em 2015, esse número aumentou para 3.3 bilhões, equivalente a $43 \%$ da população mundial. A despeito deste avanço significativo, não se pode negligenciar que aproximadamente quatro bilhões de pessoas ainda não têm acesso à internet. Quando se considera apenas os países menos desenvolvidos, esses números correspondem a 89 milhões de pessoas, de um total de $940 \mathrm{mi}-$ lhões. Assim, uma questão central nesse debate é como tornar possível o acesso às externalidades positivas advindas dos fluxos informacionais que as redes podem propiciar para um número cada vez maior de pessoas ao redor do mundo, inclusive para aquelas que ainda não estão integradas.

Outro referencial importante sobre o padrão de organização em redes é a do cientista político estadunidense Francis Fukuyama (1996; 2000; 2002). Para esse autor, as redes seriam formas de organização que diferem do padrão de organização burocrática no qual a autoridade manifesta-se pelas vias da racionalidade técnica e da hierarquia funcional, características identificadas por Max Weber (1999) em sua análise sobre a burocracia como forma de organização predominante nas sociedades modernas. Na definição proposta por Fukuyama:

Uma rede é um grupo de agentes individuais que têm em comum normas ou valores além daqueles necessários às transações habituais de mercado (...) as normas e os valores abrangidos nessa definição podem ir da simples norma de reciprocidade entre dois amigos até complexos sistemas de valor criados por religiões organizadas (2000: 209).

Para Fukuyama, a ascensão do padrão de organização em redes nas sociedades contemporâneas teria ocorrido na medida em que as economias nacionais foram integrando-se mais intensamente umas às outras a partir do padrão libe$\mathrm{ral} /$ capitalista e, com isso, ampliando os seus laços de interdependência. Nesse contexto, os requisitos informacionais para articular essas economias cresceram consideravelmente em complexidade, evidenciando, assim, o fracasso das corporações centralizadas e autoritárias pelo mesmo motivo que teria levado ao fracasso de estados centralizados e autoritários: a inabilidade para lidar com requisitos informacionais mais complexos.

Uma rede é diferente de uma hierarquia porque se baseia em normas comuns informais, não numa relação formal de autoridade. Neste sentido, uma rede pode coexistir com uma hierarquia formal. Os membros de uma hierarquia formal não precisam dividir entre si normas e valores além dos 
contratos de trabalho que definem sua participação; entretanto, as organizações formais podem ser superpostas com redes informais de vários tipos, baseadas em clientela, etnia ou cultura corporativa comum (FUKUYAMA, 2000: 211).

Fukuyama enfatiza que nem sempre as redes produzem resultados benéficos para todos os indivíduos que a compõem, pois em certas situações encontram-se superpostas sobre organizações formais, gerando, assim, situações potencialmente causadoras de deficiências organizacionais. Tais situações manifestam-se na forma de redes de parentesco, amizade, classe social, amor ou raça. O problema seria a falta de clareza dos valores e das normas de sustentação de suas estruturas, levando aqueles que não são membros a perceberem que uma ruptura com as relações formais, com frequência, é uma situação indesejada para aqueles que delas se beneficiam. As redes informais, em muitos casos, estão associadas às relações étnicas informais que caracterizam o nepotismo, 0 favoritismo, a intolerância, a consanguinidade e os arranjos personalistas e não transparentes. A esse respeito, pode-se dizer que as redes são tão antigas quanto as sociedades humanas, inclusive podendo ser consideradas a forma predominante de organização em sociedades pré-modernas.

Em certo sentido, muitas das instituições que associamos à vida moderna, como contratos, o controle da lei, constitucionalismo e a separação institucional dos poderes, forma concebida para neutralizar os defeitos nas relações informais de redes. É por isso que Max Weber e outros intérpretes da modernidade afirmaram que sua essência é a substituição da autoridade informal pela lei e por instituições transparentes (Fukuyama, 2000: 212).

Assim, as redes podem, quando corrigidas tais distorções, tornarem-se um padrão de organização capaz de coexistir de modo eficiente com hierarquias formais. Até porque, estas últimas não podem ser extintas totalmente, uma vez que custos de transação sempre são gerados pela impossibilidade de se produzir confiança mútua generalizada entre um grande contingente de indivíduos, o que não permite eliminar por completo o padrão de organização burocrática como imperativo ordenador. Fukuyama defende que uma rede deve ser entendida não apenas como organização social, como o faz Castells, mas principalmente como capital social. Desse modo, seria possível ter um maior discernimento sobre as funções econômicas que estas podem vir a desempenhar. A indisfarçada linhagem liberal na qual ele se filia o faz derivar o conceito de capital social do conceito de rede. Na seção seguinte abordaremos melhor este ponto. 


\section{Capital social, cultura e desenvolvimento}

Nas ciências econômicas, com mais frequência do que nas ciências sociais, são recorrentes as narrativas que insistem em atrelar a questão do desenvolvimento a um conjunto de racionalizações econômicas desvinculadas dos contextos socioculturais sobre os quais se tenta intervir, mesmo quando em certos casos sejam promovidos cenários de eficiência econômica que resultam em um grande custo social e humano, vide a flexibilização de direitos e garantias sociais incorporados à condição de cidadania dos trabalhadores nos últimos três decênios em países capitalistas ocidentais. Tais narrativas, senão chegam a desconsiderar a interpenetração dos diferentes níveis da experiência humana, no mínimo percebem-na primordialmente como configuradora de um conjunto de normas e valores voltados para a maximização de interesses individuais.

O economista argentino Bernardo Kliklisberg (2000), atento para essa situação, defende que a estabilidade financeira não pode se impor dissociada da estabilidade política, que, por sua vez, não se viabiliza totalmente sem certos graus de igualdade e de justiça social. Para ele, as transformações institucionais só ocorrem quando os problemas financeiros e sociais são atacados ao mesmo tempo. Com base nesse tipo de raciocínio, o Banco Mundial, na década de 1990, passou a considerar na avaliação de seus projetos de desenvolvimento quatro formas de capital: capital natural, decorrente dos recursos naturais disponíveis em um país; capital financeiro, que se manifesta pela produção, por parte da sociedade, de uma infraestrutura, de bens de capital, de capital financeiro, imobiliários, entre outros; capital humano, considerado a partir dos níveis de saúde, de nutrição e de educação de um povo; e, por fim, capital social, que estaria vinculado à capacidade de uma sociedade estreitar laços de confiança interpessoal e redes de cooperação voltadas para a produção de bens coletivos.

Para o Banco Mundial, capital social refere-se às instituições, relações e normas sociais que dão qualidade às relações interpessoais em determinadas sociedades. Aqui, a coesão social é percebida como fator decisivo para a geração de prosperidade econômica e de desenvolvimento sustentado. Uma definição conceitual que sintetiza bem essa posição é a seguinte: "capital social é a argamassa que mantém as instituições em contato entre si e as vincula ao cidadão visando à produção do bem comum" (D’ARAÚJO, 2003: 10).

Apesar da utilização relativamente recente do conceito de capital social pelo Banco Mundial, nas ciências sociais, remete-nos à uma preocupação e a um debate iniciados na década de 1980. Os sociólogos Pierre Bourdieu (1986; 
1992) e James Coleman $(1988 ; 1990)$ e o cientista político Robert Putnam (2000; 2002) foram decisivos para lhe conferir maior notoriedade e diferentes usos conceituais.

Para Bourdieu, capital social "é a soma dos recursos reais ou virtuais que um indivíduo ou um grupo possuem em virtude de pertencer a uma rede durável de relações, mais ou menos institucionalizadas, de conhecimento e reconhecimento mútuos" (BOURDIEU in BOURDIEU; WACQUANT, 1992). Os recursos gerados por um grupo ou instituição viabilizar-se-iam pela base de solidariedade existente entre os seus integrantes. Disto se depreende que as redes correspondem ao conjunto de relações sociais que podem oportunizar aos agentes recursos econômicos, sociais, culturais e simbólicos que permitir-lhes o acesso e a fruição de posições sociais privilegiadas na extensão do espaço social como um todo ou, até mesmo, de modo mais específico, posições hegemônicas em um determinado campo (BOURDIEU, 1986).

Aqui, cabe salientar que Bourdieu (2004) define um campo como um mercado onde agentes se comportam como jogadores e onde as posições destes estão correlacionadas às suas posições em um espaço social mais amplo que está estruturado por quatro tipos de capital: econômico, cultural, social e simbólico. Apesar de diferirem entre si, todos os tipos de capital manifestam-se na forma de uma propriedade, de um bem. Esta é a verdadeira essência sociológica do conceito de capital. Portanto, assim como os demais, o capital social é assimétrico, uma vez que pressupõe que se uns o possuem, outros ou o possuem menos ou dele são desprovidos. Ademais, por ser acumulável, é produtor de diferenciação social. Por isso, trata-se de um conceito importante para a explicação de desigualdades, dado que é um dos recursos utilizados pelos agentes nas lutas pela conquista ou manutenção de poder no mundo social.

Bourdieu não nega a primazia do capital econômico enquanto suporte para a obtenção de outras formas de capital, mas entende que o capital social também viabiliza o acesso aos outros tipos de capital, inclusive o econômico. Isso não implica dizer que haja uma equivalência estrutural entre ambos na explicação das posições ocupadas pelos agentes nos espaços sociais ou mesmo em um campo específico.

No "estruturalismo construtivista" de Bourdieu (2004, p. 157), os "agentes têm uma apreensão ativa do mundo", no sentido de que constroem sua visão de mundo, entretanto, as redes, enquanto morfologia social, fazem com que tal construção opere "sob coações estruturais". Em outras palavras, as redes são modeladas pelas ações e interações dos agentes, porém, são elas que estruturam as regras, as expectativas de comportamento e os sentidos conferidos às ações e 
interações ocorridas no seu interior, fazendo com que as relações sociais entre os agentes se apresentem de forma objetivada.

Coleman $(1988 ; 1990)$, baseado em seus estudos sobre o papel das normas sociais como guias de ação e expectativas de comportamento para ajustar as ações dos indivíduos aos padrões de aceitabilidade social de um grupo ou instituição, entende que a internalização destas enfatiza o que se tem como certo ou errado e o seu não cumprimento implica em sanções reforçadoras dos seus conteúdos. Os grupos que conseguem confiar nas normas sociais de reciprocidade teriam melhores condições de promover o desenvolvimento. Como indica Lima (2001), o ponto de partida da teoria do capital social de Coleman é a teoria da escolha racional, porém, ele rejeita o individualismo extremado inerente a esta.

Coleman defende que o capital social é um bem público do qual toda a sociedade pode se beneficiar e não apenas um determinado grupo de indivíduos. Por essa razão, o mercado não seria capaz de produzi-lo adequadamente, mas apenas as forças que lhes são externas, como o governo (via ensino público) e os agentes não governamentais, como famílias, igrejas, instituições de caridade e outros tipos de associações voluntárias, por exemplo.

Para Putnam (2002), o componente básico do capital social é a confiança, sendo que esta teria como fontes geradoras as regras de reciprocidade e os sistemas de participação cívica. As primeiras correspondem à obrigatoriedade moral imposta socialmente de retribuição de um favor, implicando o não cumprimento destas na aplicação de dispositivos de coerção sobre os indivíduos que não cooperam. Os segundos correspondem aos vários tipos de associações, voluntárias ou não, denominadas comunidades cívicas, caracterizadas fundamentalmente pela cooperação horizontal entre indivíduos que se percebem como relativamente iguais a partir de um contrato moral que os une. Para esse autor: "normas [...], que fortalecem a confiança social, vingam porque reduzem os custos de transação e facilitam a cooperação. A mais importante dessas regras é a da reciprocidade" (2002: 181).

Putnam (2000), ao estudar o declínio da participação cívica nos Estados Unidos, viu nos movimentos sociais uma tendência contrária ao enfraquecimento do capital social proveniente das formas tradicionais de associação cívica. Todavia, ao comparar as duas formas de participação cívica, ele infere que as formas tradicionais caracterizar-se-iam por possuírem um maior enraizamento junto às comunidades locais. $\mathrm{O}$ fortalecimento dos movimentos sociais e, mais especificamente do chamado terceiro setor, formado por associações e entidades sem fins lucrativos, representaria uma deterioração qualitativa do estoque de capital social. Ele denomina essas formas de associação de afiliações 
de "talão de cheque", uma vez que, em suas palavras: "tais organizações não fornecem nem conectividade entre membros, nem engajamento direto em uma reciprocidade cívica, e certamente elas não representam 'democracia participativa'. Cidadania por procuração é um oxímoro" (2000: 160).

Frey (2003), seguindo a trilha analítica proposta por Putnam, adverte que os movimentos sociais e as organizações do terceiro setor, enquanto fontes primordiais de capital social, baseiam-se em laços e obrigações sociais bem mais fracos do que os que unem os indivíduos em organizações tradicionais. Em outras palavras, seria:

A vida social, o contato face-a-face que mantém unidas as sociedades e não o ativismo político em movimentos sociais, a participação em associações de terceiro setor, a colaboração em organizações sem fins lucrativos ou o envolvimento em grupos de ajuda. Segundo Putnam, esses tipos de grupos falham no concernente à sua mais importante tarefa: a promoção da confiança social" (FREY, 2003: 169).

Por sua vez, Fukuyama (1996), como Putnam, enfatiza que a confiança mútua entre os atores sociais baseia-se no capital social e que este é fator decisivo para a viabilização de prosperidade econômica de uma nação. Para ambos, a confiança corresponde à expectativa de reciprocidade decorrente das normas partilhadas pelos membros de uma comunidade. $\mathrm{O}$ melhor aproveitamento das oportunidades surgidas em uma comunidade seria consequência da crença de que é possível confiar, aumentando a possibilidade de colaboração.

Fukuyama inscreve-se em uma tradição de pensamento social que tem como principais fontes de inspiração as obras clássicas de Alexis de Tocqueville (2004) sobre a formação da democracia nos Estados Unidos e de Max Weber (1990) sobre a influência da ética protestante na formação do capitalismo. Por isso, defende a cultura, os valores morais e os laços de confiança social como fatores que dão suporte e estimulo à economia de uma sociedade. A partir de estudos comparativos de caráter qualitativo, procura demonstrar que sociedades dotadas de forte capital social possuem uma boa base para o desenvolvimento e aquelas nas quais os níveis de desconfiança são generalizados em seu interior impõem uma espécie de ônus social a qualquer tipo de atividade econômica. Nesse sentido, entende que:

O capital social não é distribuído uniformemente entre as sociedades. Algumas mostram uma maior propensão à associação mais acentuada do que outras, e as formas preferidas de associação diferem. Em algumas, a família 
e o parentesco são as formas primárias de associação; em outras, as associações voluntárias são muito fortes e servem para desligar as pessoas de suas famílias (1996: 43).

Fukuyama (2002), diferentemente de Coleman, ao defender a importância da confiança mútua entre as pessoas no que diz respeito à busca pela prosperidade econômica, defende que a geração de capital social tem no livre mercado um fator positivo, já que este seria um fator de contraposição à existência de um Estado forte. Um Estado forte produziria uma ordem hierárquica que mina a capacidade da sociedade e do mercado de criarem capital social, principalmente em decorrência de políticas ineficazes e atos de improbidade que geram desconfiança. Argumenta que os mercados são capazes de produzir capital social mesmo quando as intenções dos agentes estão voltadas para a obtenção de um resultado particular. Em suas palavras: "a visão de que capital social é um bem público é errada. Ele pode ser produzido por mercados privados porque seria do interesse dos indivíduos egoístas produzi-lo" (2002, p. 264). Em oposição à Coleman, Fukuyama afirma que:

A corporação que exige um alto grau de honestidade e civilidade em seu atendimento aos clientes, ou a empresa que retira imediatamente um produto com defeito nas prateleiras das lojas, ou o diretor executivo que aceita uma redução em sua remuneração para mostrar solidariedade com seus funcionários durante uma recessão; não estão agindo de forma altruísta: cada um tem um interesse a longo prazo numa reputação de honestidade, confiabilidade, qualidade e integridade, ou simplesmente de ser um grande benfeitor. Essas virtudes passam a ser ativos econômicos e como tais são buscadas por indivíduos e empresas interessados somente nos lucros (2002: 264).

Desse modo, o capital social, ao mesmo tempo em que é entendido como produtor de externalidades positivas, isto é, de benefícios à sociedade, mesmo quando produzido por motivos egoísticos, também pode ser um subproduto dessas externalidades. A esse respeito, Fukuyama afirma que um exemplo disto encontra-se na análise clássica de Weber (1990) sobre o caso dos puritanos que em suas buscas pelo acúmulo de capital, baseadas na frugalidade e na autodisciplina, procuravam demonstrar o status de escolhidos aos olhos de Deus.

Todavia, Fukuyama desconsidera que, se o mercado pode ser importante na promoção de cooperação horizontal, assim como o Estado, também pode praticar ações verticalizadas que negligenciam a percepção dos demais atores sociais envolvidos, como das comunidades com as quais as empresas privadas 
procuram estreitar laços de confiança, por exemplo. A esse respeito, o sociólogo francês Guy Hermet entende ser necessário considerar que:

As comunidades situadas na periferia do desenvolvimento manifestam uma exigência adicional que lhes é própria: contrariamente aos cidadãos das antigas democracias, já habituados a não "encarnarem-se substancialmente" ou ativamente nas opções que lhes propõem seus representantes, os membros de outras comunidades - comunidades de possamento. Para que façam seu um projeto, é preciso sempre que possam personificar nele seus desejos, antes de concordarem em empregar nele esforços. Por exemplo, um equipamento de irrigação imposto na "marra" pode suscitar a indiferença ou até mesmo a rejeição, que em curto prazo o farão inútil, enquanto que outro programa, concebido, mesmo que apenas em alguns pontos, a partir das indicações de seus futuros usuários, tem maiores probabilidades de ser bem recebido e posteriormente, mantido em funcionamento (2002: 99-100).

Nesse sentido, o desenvolvimento de projetos comunitários, por exemplo, deve ser pensado para além de ações baseadas em formas de confiança verticalizada, não importando se tais projetos decorram de iniciativas do Estado ou do mercado. A esse respeito, Putnam diverge de Fukuyama, pois entende que o capital social determina a qualidade das instituições de uma comunidade cívica e solidária, já que os seus membros costumam cooperar sem segundas intenções. Ou seja, para Putnam, quando atores sociais do mercado agem visando à consecução de algum tipo de interesse privado, isto tende a fragilizar a relação de confiança.

O historiador econômico estadunidense David Landes (2002), também seguindo uma linha interpretativa de inspiração weberiana, defende que cultura e desenvolvimento econômico caminham lado a lado. Exemplos disso seriam os casos de grupos étnicos minoritários que prosperam economicamente em países para os quais migraram: alemães e italianos no sul do Brasil; judeus e calvinistas na Europa; indianos no leste da África; entre outros. Nessa mesma linha, o ensaísta político argentino Mariano Grondona defende que:

O paradoxo do desenvolvimento econômico é que os valores econômicos não bastam para garanti-los. O desenvolvimento econômico é importante demais para ficar inteiramente por conta dos valores econômicos. Os valores aceitos ou negligenciados por um país estão dentro do campo cultural. Podemos, portanto dizer que o desenvolvimento econômico é um processo cultural (2002: 91). 
Para D’Araújo (2003), a cultura é um fator importante na criação de valores e de normas estimuladoras do estreitamento dos laços de confiança entre atores sociais e, por conseguinte, na geração de um capital social capaz de contribuir para o desenvolvimento econômico. Porém, a referida autora entende que este não é um instrumento que opera isoladamente, pois não é substituto de nada, assim como o mercado não é substituto do Estado.

Tendo em vista que capital social pressupõe certa capacidade dos indivíduos cooperarem entre si em torno de objetivos comuns, com base em normas de caráter informal, faz-se necessário distinguir, já que estamos tratando com recursos alocados, isto é, os modos como ele pode ser instrumentalizado:

(a) Capital social instrumentalizado pelo indivíduo, a partir de sua rede egocentrada, com possibilidades de alocação dos recursos individualmente. É o caso, por exemplo, de ajudas diversas prestadas por vizinhos, ou do suporte dado por familiares por ocasião de doenças etc. (b) capital social instrumentalizado pela comunidade, a partir de recursos que, embora gerados pelas redes egocentradas, traduzem-se em ampliação da esfera pública. É o caso, por exemplo, de práticas associativas ou outras formas de manifestações políticas em que os indivíduos participam, de certo modo induzidos pelo círculo de relações a que pertencem (FONTES; EICHER, 2004: 21).

O primeiro tipo corresponde àquele que se manifesta no âmbito da esfera privada, onde se fazem presentes vínculos sociais mais fortes entre os indivíduos. Já o segundo tipo corresponde aos vínculos sociais mais fracos, relacionados à capacidade de associação na esfera pública, remetendo àquilo que Putnam (2002a) chama de cultura cívica. A geração de capital social decorre dos campos de sociabilidade nos quais estão inseridas as ações dos indivíduos. A cooperação depende do significado atribuído aos benefícios que desta pode advir, seja na esfera privada ou na pública.

A esse respeito, a contribuição do sociólogo estadunidense Mark Granovetter (1983) para o debate é fundamental, pois indica que os vínculos sociais mais fortes ou laços fortes e os vínculos sociais mais fracos ou laços fracos são elementos estruturantes de estoque de capital social diferentes. Os laços fortes funcionam no sentido de disponibilizar recursos decorrentes de relações sociais predominantemente caracterizadas pela intensidade dos contatos e por certa proximidade social entre os indivíduos. Por sua vez, os laços fracos possuem na mobilização de recursos disponíveis na esfera pública a sua principal característica, o que corresponde à geração de um capital social que possibilita $\mathrm{o}$ 
compartilhamento dos recursos alocados entre os membros de uma comunidade política. Tal ocorrência só seria possível em contextos sociais que estimulam a vitalização da esfera pública como meio de promoção de participação dos indivíduos na vida social.

Granovetter (1985), inscrevendo-se na tradição sociológica weberiana, procura trazer novas respostas às perguntas deixadas de lado pela teoria econômica. Todavia, de modo algum, pretende substituir as respostas desta última, inclusive, reconhece a validade da abstração do homo oeconomicus para a ciência econômica e a sua importância na análise da oferta e da demanda, mas considera necessário acrescentar aos pressupostos básicos do comportamento do ator econômico as "motivações não econômicas". Nesse sentido, ele entende que os fenômenos econômicos manifestam-se em três níveis: da ação econômica, dos resultados econômicos (como os preços e os salários) e das instituições econômicas. Com isso em mente, sugere que, de um ponto de vista sociológico, esses três níveis sejam compreendidos da seguinte maneira: a ação econômica é uma forma de ação social; a ação econômica é socialmente situada; e as instituições econômicas são construções sociais.

Não se pode negar que Granovetter mantém a perspectiva do individualismo metodológico e da hipótese da racionalidade (as explicações dos fenômenos sociais se fundamentam nas motivações e nos comportamentos dos indivíduos), mesmo que as relativize. Para ele, o indivíduo é um ser racional que busca a maximização de sua utilidade e que, para tal, recorre aos cálculos de custo e benefício. $O$ ponto de partida da economia e também da sociologia econômica seria basicamente o mesmo: a ação orientada para a satisfação de necessidades em situação de escassez.

No entanto, Granovetter relativiza essa primeira avaliação, pois na sua proposição teórica, a ação econômica é entendida como um tipo de ação social, alinhando-se, assim, às perspectivas analíticas de autores como Weber (1999) e Polanyi (2000). Para além dos objetivos econômicos, os atores sociais perseguem também objetivos sociais, como sociabilidade, reconhecimento e poder. É nesse sentido que a ação econômica é "socialmente situada", já que os indivíduos não agem de maneira plenamente autônoma e suas ações estão imersas em sistemas concretos e contínuos de relações sociais, isto é, em redes sociais. Aqui, temos a tese da imersão social (embeddedness) das ações econômicas, que se subdivide em dois tipos: a imersão relacional, correspondente às relações pessoais mais imediatas (família, amigos etc.), os chamados laços fortes; e a imersão estrutural, correspondente às relações mais afastadas (conhecidos), os chamados laços fracos. 
Granovetter (1985) argumenta que as ações dos atores sociais são condicionadas por seus pertencimentos às redes de relações interpessoais. Desse modo, o mercado não é entendido como um livre jogo de forças abstratas, de simples oferta e procura entre indivíduos atomizados e anônimos, mas como um conjunto de ações imersas em redes concretas de relações sociais. Esta abordagem oferece um referencial valioso para a compreensão sociológica de situações como: a inserção dos indivíduos no mercado de trabalho; a geração de desenvolvimento socioeconômico; o êxito ou fracasso de micro e pequenas empresas; a dinâmica de funcionamentos de grupos econômicos; e a produção de confiança em redes de sociabilidade, inclusive, em redes migratórias.

\section{Redes sociais, mercado de trabalho e processos migratórios}

A nova sociologia econômica, inaugurada por Mark Granovetter (1985) e pelo sociólogo sueco Richard Swedberg (1990; 1994; 2003), apresenta uma contribuição relevante para a compreensão das configurações do mercado de trabalho e dos fluxos migratórios nacionais e internacionais, isto porque os referidos autores destacam o papel decisivo que as redes sociais desempenham na inserção e na mobilidade dos indivíduos nesses dois campos de pesquisa. $O$ primeiro, por motivos já expostos na seção anterior. O segundo, por propor uma abordagem na qual se entende que os mercados não se desenvolvem e funcionam apenas na base da dinâmica estrita da maximização das utilidades individuais, mas sofrem também influências de arranjos e instituições sociais e políticas, isto é, daquilo que Swedberg (1994) denomina "estrutura social do mercado". Como indica Steiner:

A sociologia econômica não pretende, obviamente, recusar categoricamente a teoria econômica; nem pretende, menos ainda, considerá-la como ciência definitiva que não deixa dúvidas, dado que seus princípios explicativos são muito parciais para isso. A sociologia econômica busca seu caminho unindo análises sociológicas e econômicas de maneira a obter uma explicação melhor para os fatos socioeconômicos do que a explicação fornecida pela teoria econômica (2006: 28).

Lima (2013) destaca que os esforços analíticos empreendidos pela nova sociologia econômica se situam na contramão das perspectivas que celebram a burocratização crescente das organizações e a racionalização das formas de recrutamento e manutenção da força de trabalho. Mesmo porque a ênfase é dada à maneira como as relações sociais estão imersas nas ações econômicas 
e como estas são afetadas e influenciadas no seu desenvolvimento por aquelas. A nova sociologia econômica tenta oferecer ferramentas teóricas que vão além do reducionismo econômico, pois entende que os mercados não devem ser compreendidos nos limites estritos da lógica econômica, mas, sim, de toda uma conjunção de fatores. Um desses fatores seria a percepção de que as redes sociais, como aquelas construídas entre trabalhadores, por exemplo, influenciam na obtenção e na manutenção de uma oportunidade de trabalho ou de um emprego (GRANOVETTER, 1995; LIMA; CONSERVA, 2006).

Nos estudos sobre redes, as relações sociais - sejam densas (laços fortes) ou difusas (laços fracos) - ajudam a determinar a posição de cada indivíduo na arena das vantagens e privilégios da estrutura social (TRUZZI, 2008). A força de um laço social é determinada pela combinação de intensidade emocional, tempo, intimidade e serviços recíprocos que o caracterizam. Portanto, um laço forte caracteriza-se por relações pessoais baseadas na família, amizade e "comunidade". Por sua vez, laços fracos estão ligados às relações mais superficiais, não duradouras ou profundas, como entre colegas de trabalhos, de escola etc. (GRANOVETTER, 1983).

O trabalho referencial de Granovetter (1995) constatou que, para profissionais liberais (como professores, técnicos e executivos), os laços fracos tendem a ser mais importantes no momento de se conseguir uma ocupação, uma vez que diferentes informações circulam para os indivíduos por meio destes. Isto é, pessoas próximas têm a tendência de frequentar os mesmos círculos, recebendo, assim, as informações que já conheciam, ou seja, é mais provável que um indivíduo receba novas informações de alguém que percorra outros círculos de amizade. Portanto, as ações sociais de um indivíduo, como a sua própria mobilidade ocupacional, são orientadas pelo seu pertencimento a uma diversificada rede social.

Granovetter (1995) insiste no papel central das relações pessoais concretas e das estruturas sociais (ou "redes") no desenvolvimento da confiança entre os indivíduos. Nesse sentido, no caso do mercado de trabalho, a adequação entre o indivíduo e o emprego não se realizaria plenamente por meio do mecanismo dos preços (lei da oferta e da procura), uma vez que os mais diversos tipos de mecanismos podem promovê-la, entre os quais, destacar-se-iam: procedimentos impessoais, como anúncios e agências de emprego; candidatura espontânea, mediante procura direta junto ao possível empregador; e contatos pessoais. Em outras palavras, ao invés de dependerem apenas da informação veiculada por indicadores econômicos, as oportunidades de trabalho são transmitidas como "subproduto" das relações sociais. Por isso, a importância dos laços fracos residir 
exatamente no estabelecimento de pontes entre as redes, permitindo ao indivíduo 0 acesso aos mais diversificados universos sociais e à uma maior variedade de informações sobre oportunidades de trabalho. Nesses casos, não seriam as escolhas racionais individuais, mas, sim, os seus laços sociais que influenciam mais diretamente as inserções e as trajetórias no mercado de trabalho. Em sendo uma sociedade um conjunto de redes de interações sociais, o que disto se depreende é que quanto maior o número de redes acessadas por um indivíduo, maiores serão suas chances de inserção no mercado de trabalho e, por conseguinte, maior será a sua mobilidade dentro deste.

Outra contribuição relevante a respeito da influência das redes sociais e do capital social no acesso às oportunidades de trabalho é de Nan Lin (2001), sociólogo chinês radicado nos EUA. Lin propõe uma análise que enfatiza o lugar ocupado por um indivíduo em uma rede organizacional, objetivando compreender a estrutura relacional que possibilita definir o tamanho e a quantidade de capital que o indivíduo tem acesso em um grupo, a fim de determinar a composição do capital social. O entendimento proposto é o de que a ideia de capital pressupõe uma distribuição desigual entre os indivíduos que compõem um grupo.

Ronald Burt (1992), sociólogo estadunidense, em seu estudo sobre a progressão de diretores de uma grande empresa de tecnologia, demonstrou o papel das redes de relações nas promoções internas. Não muito distante da proposição teórica de Granovetter sobre a importância dos laços fracos na estruturação de uma rede, ele formulou a teoria dos buracos estruturais. Em suas palavras: "os buracos estruturais são os vazios entre contatos não redundantes" (Ibid: p. 47). Aqui, a compreensão é de que quanto mais uma rede possuir buracos estruturais, tanto mais informações e meios de controle serão oportunizados para os que nela estão inseridos. Nesse sentido, os indicadores empíricos de redundância de um contato seriam: a coesão, uma vez que contatos fortemente conectados uns aos outros provavelmente fornecem informações similares e, desse modo, proveem os mesmos benefícios ao ator; e a equivalência estrutural, pois contatos que, independentemente das relações que tenham entre si, ligam-se às diferentes partes de uma mesma rede apenas por um ator, têm as mesmas fontes de informação e, por isso, proporcionam benefícios redundantes.

Burt (1992), assim como Lin (2001), parte do pressuposto de que existe entre os membros de um grupo uma distribuição desigual de capital social. Na prática, esse aspecto não coesivo resultaria da posição privilegiada que um determinado ator possui em uma rede pessoal ou organizacional, posição esta que faz com que os demais atores precisem passar por ele para entrarem em contato 
uns com os outros. A centralidade da posição ocupada confere ao ator a possibilidade de controlar as relações dos demais, permitindo-lhe beneficiar-se do que ele sabe e do que os outros desconhecem, assim, lhe é possível mobilizar sem intermediários os atores que estão inseridos em uma rede.

Guimarães (2009, p. 161) chama atenção para o fato de que o acesso às oportunidades de trabalho, em muitos casos, ocorre por meio de mecanismos que não estão submetidos à "racionalidade e às instituições especializadas do mercado", mas, sim, "pelas redes tecidas pelos indivíduos em suas distintas esferas de sociabilidade no curso da vida cotidiana". A esse respeito, ela afirma que "o debate sobre $o$ acesso às oportunidades de trabalho, e em particular à circulação de informações no mercado de trabalho é devedor das formulações de dois autores, Mark Granovetter e Nan Lin" (Ibid: 169). Isto porque, ambos, demonstraram que redes pessoais acionadas na procura de trabalho são uma via importante de estruturação do acesso às ocupações. A referida autora enfatiza que esses tipos de análise possibilitam à sociologia do trabalho não se prestar apenas a retratar os resultados da operação do mercado de trabalho expressos na dinâmica da estrutura do emprego. Dito de outro modo:

O funcionamento do mercado de trabalho, como de resto de outros mercados, demanda, assim, que estruturas sociais subjacentes sejam examinadas de maneira a se compreender as formas de transmissão de oportunidades. Nesse sentido, fica evidente que se trata de um processo que não se resume a mecanismos usuais de coordenação mercantil via sistema de preços (no caso o preço pelo qual se admite trabalhar ou, visto por outro ângulo, o preço pelo qual se aceita recrutar um trabalhador) (GUIMARÃES, 2009: 163).

Tem sido a partir desse debate que as pesquisas sobre migração se apropriam do conceito de redes sociais, utilizando-se do conceito de redes migratórias. Aqui, entenda-se, o conjunto de relações interpessoais que vinculam imigrantes, emigrantes retornados ou candidatos à migração com parentes, amigos ou compatriotas, quer seja no país de destinou ou no de origem (TILLY, 1978; MASSEY; GOLDRING, 1992). A análise de redes migratórias permite demonstrar como ações micro-individuais estão embebidas e interconectadas em redes globais que conectam as sociedades de origem e de destino por meio de laços sociais que fornecem suporte ao migrante, desde o momento em que este decidiu deixar seu país de origem (MARTES; FAZITO, 2010).

Os processos migratórios não expressam apenas mobilidade individual, mas, sobretudo, um movimento físico e social que se realiza pelas redes de relações 
sociais criadas pelo migrante (TILLY, 1978). Tais relações atuam diretamente no processo de migração, proporcionando informações importantes, como indicações de emprego e moradia, o que tende a facilitar as ações do possível migrante (SOARES, 2002; RESENDE, 2005).

A análise de redes migratórias ajuda a compreender não apenas os motivos que levam as pessoas a migrarem, mas também os motivos para a escolha do destino e o modo como se relacionam na sociedade receptora (TILLY, 1978). Para Martes e Fazito (2010), a análise de redes sociais contribui para a construção de abordagens teóricas diferentes das perspectivas econômicas. Esse tipo de análise permite perceber que as redes sociais informais, constituídas por laços solidários entre familiares e amigos, facilitam o deslocamento de migrantes e garantem uma mobilidade social na sociedade receptora, entre outras coisas, porque fornecem aos recém-chegados contatos de trabalho e estimula a formação de um empreendedorismo étnico, com a abertura de negócios voltados à "comunidade étnica" (HALTER, 1995; WALDINGER et al, 2000; BONACICH; MODELL, 1980). Ou seja, todo o projeto migratório de um indivíduo (deslocamento e adaptação na sociedade receptora) é afetado diretamente pelo número de contatos sociais que ele possui, ou, pela quantidade de seu capital social: quanto mais capital social tiver, mais vantagem provavelmente obterá.

Estudos sobre redes sociais e comunidades transnacionais costumam focar-se no aspecto "solidário" presente na ideia de capital social formulada por $\mathrm{Pu}$ tnam (2002), e não de um recurso utilizado na reprodução das desigualdades, como formulado por Bourdieu (1986). Para Putnam, o conceito de capital social expressa a "essência sociológica" de uma vida comunal, uma vez que é tido como uma rede de conexões, lealdades, investimentos e obrigações mútuas, desenvolvida a partir de laços solidários. Ou seja, o enfoque se dá nas relações solidárias e recíprocas desenvolvidas entre os indivíduos. Como resultado, as pesquisas sobre redes e migração consideram crucial a existência de uma "rede solidária" que funcione entre os conterrâneos que tentam se ajudar na sociedade de destino.

Massey e Goldring (1992) demonstraram que o sucesso dos pioneiros mexicanos que migraram para os Estados Unidos tornou-se um forte estímulo para muitos outros indivíduos migrarem e, gradualmente, contribuiu para o fortalecimento de redes sociais internacionais que passaram a facilitar o movimento de novos migrantes. A mesma situação tem ocorrido com certas regiões do Brasil, como os fluxos existentes entre a cidade de Governador Valadares (MG) e algumas regiões dos EUA (FUSCO, 2002; SOARES, 2002); de Criciúma para os EUA (ASSIS, 2003); e de outros pontos regionais para países específicos no 
exterior, como para Portugal (MACHADO, 2005), Massachusetts/ EUA (MARTES, 1999), Japão (SASAKI, 2000), por exemplo.

Com certa frequência, esse tipo de análise limita-se a traçar as rotas, o tamanho e a importância das redes sociais no processo migratório, desconsiderando as diferentes formas que os contatos estabelecidos podem ser utilizados por migrantes com características sociais distintas ou como esses laços sociais, ao mesmo tempo em que ajudam e incluem alguns, funcionam como instrumentos de controle e exclusão de outros. Nesse sentido, é preciso considerar que tais análises incorrem em "erro" semelhante ao dos teóricos "econômicos" quando reduzem os motivos para migrar basicamente a um único fator, substituindo, assim, o "homo oeconomicus" por um "homo solidarius". Para muitos daqueles que se alinham a essa perspectiva analítica, o migrante é entendido como um ator social que se relaciona dentro da sua comunidade a partir de relações pautadas pela reciprocidade e solidariedade. Aqui, o que se negligencia ou minimiza não é apenas a ocorrência de conflitos e competições internas em um grupo, mas, acima de tudo, que tais ocorrências, com bastante frequência, são fatores de exclusão de certos indivíduos ao acesso às oportunidades que o pertencimento a uma determinada rede de sociabilidade pode propiciar (MARTES; FAZITO, 2010).

\section{Considerações finais}

Para efeito não de conclusão, mas tão somente de breves e provocativas considerações finais, sem pretensões de caráter peremptório, advogamos que, por mais úteis e dotados de capacidade heurística que sejam os conceitos de redes e capital social, não podemos tomá-los como fatores que por si só explicam o desenvolvimento socioeconômico de determinados países, a falta de prosperidade de determinadas comunidades, o acesso a melhores oportunidades de trabalho e inserções bem sucedidas nas localidades para as quais se decide migrar. Afinal, quando estamos lidando com a dinâmica das interações humanas em sociedades capitalistas, outras formas de capital, como o capital econômico e o capital cultural, apresentam-se como categorias sociológicas que, se não necessariamente se sobrepõem ao capital social enquanto fatores explicativos, com certa frequência, podem condicionar a maior ou menor eficácia dos seus usos pelos agentes socais.

Dito isso, ao considerarmos os diferentes sentidos que os conceitos aqui tratados remetem, devemos ter em mente que, com a intensificação dos fluxos econômicos, culturais, informacionais e migratórios promovidos pela globalização, 
temos a emergência de um cenário no qual a dualidade acesso/ inclusão e controle/ exclusão, inerente às redes e ao capital social, não apenas pode atuar na promoção de prosperidade socioeconômica para determinadas sociedades e comunidades, de melhores oportunidades de inserção individual no mercado de trabalho e de mitigação dos custos materiais e pessoais envolvidos no ato de migrar, mas, também, pode configurar constrições sociais para os indivíduos, grupos e sociedades.

Para finalizarmos, reiteramos que, em sendo o capital social uma forma de capital, a assimetria que lhe é imanente pressupõe que se alguns o possuem, outros dele são desprovidos ou o possuem menos. Desse modo, como estamos falando de um recurso chave para transitar em uma rede, tanto no que se refere à abertura de caminhos a serem seguidos, quanto à imposição de dificuldades para se seguir em uma determinada direção, a dualidade acesso/ inclusão e controle/ exclusão jamais pode ser deixada de lado quando de sua utilização para fins analíticos. Na prática, isto implica em não se perder de vista que o capital social produz níveis diferenciados de acesso a determinados recursos e oportunidades e, por isso, também opera no sentido de reproduzir e reforçar desigualdades. Dito de outro modo, parafraseando um insight da sabedoria popular: "a mão que dá é a mesma que tira”.

\section{Referências}

ASSIS, G. De Criciúma para o mundo: os novos fluxos da população brasileira: gênero e rearranjos familiares. In: MARTES, A. C. B., FLEISCHER, S. (Orgs.) Fronteiras cruzadas: etnicidade, gênero e redes sociais. São Paulo: Paz e Terra, 2003, pp. 199-230.

BARNES, J. A. Class and committees in a Norwegian Island Parish. Human Relations, London, vol. 7 n. 1, 1954, pp. 39-58.

BONACICH, E.; MODELL, J. The economic basis of ethnic solidarity. Berkeley: University of California Press, 1980.

BOURDIEU, P. The Forms of Capital. In: Richardson, J. G. (ed.): Handbook of Theory and Research for the Sociology of Education, New York/Westport/London, 1986, pp. 241-258.

Coisas ditas. São Paulo: Brasiliense, 2004.

BOURDIEU, P.; WACQUANT, L. An Invitation to Reflexive Sociology, Chicago: University of Chicago Press, 1992.

BURT, R. Structural holes: the social structure of competition. Havard UP, 1992.

CASTELLS, M. A sociedade em rede. - A era da informação: economia, sociedade e cultura. $6^{\text {a }}$ ed. São Paulo: Paz e Terra, Vol. I, 2002. 
COLEMAN, J. Social Capital in Creation of Human Capital. American Journal of Sociology, 94, 1988, pp. 195-120.

Foundations of Social Theory. Cambridge: Harvard University Press, 1990.

D’ARAÚJO, M. C. Capital Social. Rio de Janeiro: Jorge Zahar, 2003.

FONTES, B. S. M.; EICHER, K. A formação do capital social em comunidades de baixa renda, REDES- Revista Hispana para el Análisis de Redes Sociales, Sevilla, vol.7, n. 2, Oct./ Nov, 2004.

FREY, K. (2003), Desenvolvimento sustentável local na sociedade em rede: o potencial das novas tecnologias de informação e comunicação. Revista de Sociologia e Política, Nov, 2003, pp.165-185.

FUKUYAMA, F. Confiança. As virtudes sociais e a criação da prosperidade. Rio de Janeiro: Rocco, 1996.

. A grande ruptura. A natureza humana e a reconstituição da ordem social. Rio de Janeiro: Rocco, 2002.

Capital social. In: HARRISON, L. E.; HUNTINGTON, S. P. (Orgs.). A cultura importa: os valores que definem o progresso humano. Rio de Janeiro: Record, 2002, pp. $155-171$.

FUSCO, W. Redes Sociais na Migração Internacional: o caso de Governador Valadares. In: Textos Nepo, Unicamp, n. 40. Campinas, 2002.

GIDDENS, A. $O$ mundo em descontrole: o que a globalização está fazendo de nós. Rio de. Janeiro: Record, 2000.

GRANOVETTER, M. The Strength of Weak Ties: A Network Theory Revisited. Sociological Theory 1: San Francisco, 1983, pp. 201-233.

. Economic Action and Social Structure: The Problem of Embeddedness. American Journal Sociology, volume 91, Issue 3 (Nov), 1985, pp. 481-493.

. Getting a Job: A Study of Contacts and Careers. 2nd edition. Chicago: University of Chicago Press, 1995 [1974].

GUIMARÃES, N. A. A sociologia dos mercados de trabalho, ontem e hoje. Novos estudos. - CEBRAP [online], n.85, 2009, pp. 151-170.

HALTER, M. New Migrants in the Marketplace: Boston's Ethnic Entrepreneurs. Cambridge: University of Massachusetts Press, 1995.

HERMET, G. Cultura e Desenvolvimento. Petrópolis: Vozes, 2002.

LANDES, D. Quase toda a diferença está na cultura. In: HARRISON, L.; HUNTINGTON, S. (orgs). A cultura importa: os valores que definem o progresso humano. Rio de Janeiro: Record, 2002, pp. 39-52.

LIMA, J. C. A teoria do capital social na análise de políticas públicas. Política \& Trabalho, João Pessoa, v. 17, 2001, pp. 46-63. 
LIMA, J. C.; CONSERVA, M. Redes sociais e mercado de trabalho: entre o formal e o informal. Política \& Trabalho, João Pessoa, v. 24, 2006, pp. 73-98.

LIN, Nan. Social capital: a theory of social structure and action. Cambridge: Cambridge University Press, 2001.

MACHADO, I. J. de R. Implicações da imigração estimulada por redes ilegais de aliciamento: o caso dos brasileiros em Portugal. Ilha. Revista de Antropologia (Florianópolis), v. 7, 2005, pp. 187-212.

MARTES, A. C. B. Os imigrantes brasileiros e as igrejas em Massachusetts. In: REIS, R.; SALES, T (Orgs). Cenas do Brasil Migrante. São Paulo: Boitempo, 1999.

.; FAZITO, Dimitri. Solidarity and Social Networks. Economic Sociology - The European electronic newsletter, v. 11, 2010, pp. 43-53.

MASSEY, D.; GOLDRING, L. Continuities in transnacional migration: an analysis of thirteen Mexican communities. Washington (Paper presented at Workshop U.S. Immigration research: an assessment of data needs for future research, financed by National Research Council), 1992.

POLANYI, K. A Grande Transformação: as origens da nossa época. 2. ed. Rio de Janeiro: Elsevier - Campus, 2000.

PUTNAM, R. Bowling Alone: the Collapse and Revival of American Community. Nova York: Simon \& Schuster, 2000.

Comunidade e democracia: a experiência da Itália moderna. Rio de Janeiro: FGV, 2002.

RESENDE, R. Brasileiros no sul da Flórida - Relatos de uma pesquisa em andamento. In: MARTES. A. C. B. e FLEISCHER, S., Fronteiras cruzadas: etnicidade, gênero e redes sociais, São Paulo, Paz e Terra, 2003.

SASAKI, E. M. Dekasseguis: Trabalhadores Migrantes Nipo-Brasileiros no Japão. Campinas: UNICAMP, Núcleo de Estudos de População, 2000.

SOARES, W. Da metáfora à substância: redes sociais, redes migratórias e migração nacional e internacional em Valadares e Ipatinga. Centro de Desenvolvimento e Planejamento Regional, Universidade Federal de Minas Gerais, Belo Horizonte, 2002. STEINER, P. A sociologia econômica. São Paulo: Atlas, 2006.

SWEDBERG, R. Economics and Sociology: Redefining Their Boundaries: Conversations with Economists and Sociologists. Princeton University Press, 1990. Markets as social structures. In: Smelser e Swedberg, R. (eds). The handbook of economic sociology. Princeton: Princeton UniversityPress, 1994, pp. 255-282

Principles of economic sociology. Princeton: Princeton University Press, 2003.

TILLY, C. Migration in Modern European History. In: MCNEILL, William H.; ADAMS, Ruth S. (orgs.). Human migration, patterns and policies. Indiana University Press, 1978, pp. 48-72. 
TOCQUEVILLE, A. A Democracia na América. Vol I e II. São Paulo: Martins Fontes, 2004 [1835].

TRUZZI, O. Redes em processos migratórios. Tempo Social (USP. Impresso), v. 20, 2008, pp. 199-218.

WALDINGER, R.; ALDRICH, H.; WARD, R. Ethnic Entrepreneurs. In: R. Swedberg, (ed.), Entrepreneurship - The Social Science View. Oxford: Oxford University Press, 2000, pp. 356-388.

WEBER, M. A ética protestante e o espírito do capitalismo. $3^{\text {a }}$ edição. Lisboa: Editorial Presença, 1990 [1905].

Economia e Sociedade: fundamentos da Sociologia Compreensiva. Vol. II Brasília, Editora da UNB, 1999 [1922].

Recebido em 25/11/2016

Aprovado em 19/02/2018

\section{Como citar este artigo:}

BARBOSA, Attila Magno e Silva; MARTINS Jr., Angelo. Redes e capital social: usos possíveis e eventuais limitações enquanto categorias sociológicas. ContemporâneaRevista de Sociologia da UFSCar, v. 8, n. 1, jan.- jun. 2018, pp. 239-264. 